\title{
Pharmacological Effect of Muntingia calabura Leaves on the Expression of sod1 and sod2 in Drosophila
}

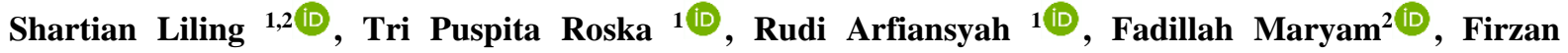 \\ Nainu 1 , * (D) \\ 1 Faculty of Pharmacy, Universitas Hasanuddin, Makassar 90245, Indonesia \\ 2 Sekolah Tinggi Ilmu Farmasi Makassar 90245, Indonesia \\ * Correspondence: firzannainu@ unhas.ac.id;
}

Scopus Author ID 57120069200

Received: 2.01.2021; Revised: 26.01.2021; Accepted: 29.01.2021; Published: 7.02.2021

\begin{abstract}
The lifespan of Drosophila melanogaster can last longer when consuming ethanol extract of Muntingia calabura leaves (EMCL) before starvation. Lifespan extension can be affected by several factors, including the increased expression of endogenous antioxidants. This study aimed to assess the level of endogenous antioxidants sodl and $\operatorname{sod} 2$ in D. melanogaster upon ingestion of ethanol extract of $M$. calabura leaves (EMCL) before starvation. Fifty D. melanogaster were divided into five groups: healthy control group, starvation control group, and three groups of EMCL-treated: $0.2 \%$ group, $1 \%$ group, and 5\% group. Each group was fed with fly food in the presence or absence of EMCL for seven days, and all groups, except the healthy control group, were subsequently subjected to a starvation procedure for seven hours. RNA extraction was performed on each group before sodl and sod2 measurements using the reverse-transcriptase quantitative PCR method. Our results revealed that the expression of $\operatorname{sod} 2$ was increased in response to starvation. On the contrary, reduced expression of sodl was observed in the starvation-treated group. Treatment of flies with EMCL at 1\% and 5\% increased the mRNA level of sodl, but did not affect the mRNA level of sod2. Taken together, our results demonstrated the potential effect of Muntingia calabura leaves in the modulation of Drosophila sodl and $\operatorname{sod} 2$ gene expression in Drosophila. Similar endogenous antioxidants are present in humans and have been associated with aging, implying that prospective pharmacological investigations are feasible to pursue in future studies.
\end{abstract}

Keywords: Muntingia calabura; sod1; sod2; antioxidant; Drosophila melanogaster.

(C) 2021 by the authors. This article is an open-access article distributed under the terms and conditions of the Creative Commons Attribution (CC BY) license (https://creativecommons.org/licenses/by/4.0/).

\section{Introduction}

Free radicals consist of one or more unpaired electrons as metabolic products of metabolism in the mitochondria [1, 2]. Production of free radicals in low concentrations has beneficial effects on the body. However, it can cause oxidative stress if they are overproduced [3-5]. Oxidative stress has been suggested to play an essential role in the induction of apoptosis, a programmed cell death $[5,6]$. Apoptosis is essential for the normal function and survival of multi-cellular organisms, including host defense against pathogenic microbes [6-8]. However, excessive apoptosis can induce harmful host responses that may impair tissue functions and may lead to physiological abnormalities [9].

In living things, cell death can be triggered by several factors: continuous starvation $[10,11]$. Cells primarily respond to starvation via the autophagy pathway, but in the event of prolonged starvation, cells may undergo autophagic cell death in addition to apoptosis [11]. 
Calorie restriction (CR) by controlled starvation has been shown to be associated with a prolonged duration of life, implying the anti-aging effect of such an approach [12]. However, at certain conditions, starvation may promote detrimental injuries to tissues [10]. Starvationinduced modifications in physiological responses, for example, extended lifespan, have been demonstrated using different types of model animals [12, 13], including in the fruit fly Drosophila melanogaster [14].

Drosophila melanogaster has been widely applied as a model system to investigate various biological phenomena in metazoan species, including the supportive role of the virus in the defense against cancerous cells [15], the mechanistic basis of cell death [16], and aseptic inflammation [17], the impeccable role of innate immunity in the fight against bacterial [18], viral [19, 20], and fungal [21] infections, and even in the continuous global efforts to discover new drug entities from medicinal plants [22-26] and/or to repurpose old drugs for new pharmacological indications [27]. In fact, just recently, D. melanogaster has been proposed as a potential model organism to study SARS-CoV-2 virulence genes and host factors responsible for the pathogenesis of COVID-19 [28].

Extended lifespan is affected by several factors, including antioxidants both exogenous and endogenous that can inhibit free radicals [3, 4]. Normally, the human body produces intrinsic or endogenous antioxidants; one of them is superoxide dismutases (SODs), the first class and one of the most important enzymatic antioxidants to inhibit reactive oxygen species (ROS), especially superoxide anion radicals [3, 29, 30]. Two SODs, CuZn-SOD (SOD1) and Mn-SOD (SOD2) are important in humans [29]. In Drosophila itself, these two SODs have been described to be important in life extension [31]. Some studies using D. melanogaster as a model organism demonstrated the involvement of endogenous antioxidants SOD1 and/or $S O D 2$ in regulating $D$. melanogaster lifespan $[31,32]$ and its improvement in the presence of a certain drug or plant extracts $[3,33,34]$.

One of the natural resources proven to have antioxidant activity in vitro and in vivo is Muntingia calabura L. [35, 36]. Previous experiments using the mice model revealed that $M$. calabura leaves extract possessed anti-aging activity, possibly reducing the level of oxidative stress [35]. Indeed, we also found that Drosophila melanogaster experienced an extended lifespan upon ingestion of ethanol extracts of Muntingia calabura leaves (EMCL) before the starvation process was initiated [Unpublished data]. Based on the currently available data, there is an indication that EMCL can extend the lifespan of D. melanogaster in stress conditions. Here we reported a study to examine the effect of EMCL on the expression of endogenous antioxidants CuZn-SOD $(\operatorname{sod} 1)$ and Mn-SOD $(\operatorname{sod} 2)$ using the starved Drosophila model.

\section{Materials and Methods}

\subsection{Plant extract preparation.}

Ethanol extract of M. calabura leaves (EMCL) samples was obtained from Makassar, South Sulawesi, Indonesia. This sample was prepared by maceration method with a ratio 1:10 of simplistic and $70 \%$ ethanol for three days in a place protected from direct sunlight with occasional stirring was performed during the process. After that, the macerated mixture was filtered then the residue was re-macerated again for three more days. Later, the filtrate was evaporated using a rotary evaporator until a thicken extract was obtained. 


\subsection{Fly stocks.}

The $w^{1118}$ Drosophila melanogaster line used in this study was generously provided by the Host and Response Laboratory of the University of Kanazawa, Japan. Flies' maintenance were carried out in standard conditions $\left(25^{\circ} \mathrm{C}, 12\right.$ hours light and 12 hours dark cycles, and standard corn-meal food). In this study, adult male flies were anesthetized in a refrigerator at $20^{\circ} \mathrm{C}$ for \pm 5 minutes before RNA extraction and gene expression analysis.

\subsection{Fly treatment and starvation induction.}

Adult male flies at the age of 10 days were prepared, assigned into five different groups, treated according to their groups, and then induced into the starvation condition (10 flies per vial, 3 vials in each group). Flies were maintained in an incubator with a steady temperature at $25^{\circ} \mathrm{C}$. Fly feeding was carried out for seven days. A group fed with standard fly food was used as the healthy control group in this experiment. Flies in the starvation control group were given standard fly food for seven days and then transferred in an empty vial for seven hours. Other groups were similarly treated as the negative control group but fed with standard fly food containing EMCL at a concentration of either $0.2 \%, 1 \%$, or $5 \%$.

\subsection{Gene Expression analysis.}

Isolation of total RNA was conducted on all treatment groups. Ten live flies from each group were transferred into a Treff tube then anesthetized in a freezer at $-20^{\circ} \mathrm{C}$ for \pm 5 minutes prior to crushing using a micropestle. Total RNA was extracted using the RNA Isolation System (Promega) reagent. The level of $\operatorname{sod} 1$ and $\operatorname{sod} 2$ were quantitatively examined by using the reverse transcriptase quantitative PCR (RT-qPCR) method. A set of sodl primer (sequence of sod 1 forward primer: 5'-AGGTCAACATCACCGACTCC-3' and sequence of sodl reverse primer: 5'-GTTGACTTGCTC AGCTCGTG-3') and a set of sod2 primer (sequence of sod2 forward primer: 5'-TGGCCACATCAACCA CAC-3'and sequence of sod 2 reverse primer: 5'-TTCCACTGCGACTCGATG-3') in a total volume of $20 \mu$ l using GoTaq $^{\circledR} 1$-Step RTqPCR System (Promega) were used, as per manufacturer's instruction. Verification of whether the expected product had been amplified was carried out based on the assigned samples' standard melt curve profile. As an internal control in the RTqPCR assay, the level of $r p 49$, a host gene responsible for the expression of ribosomal protein, was examined by using a set of rp49 primer ( $r p 49$ forward primer: 5'-AGATCGTGAAGAAGCGCACCAAG-3' and rp49 reverse primer: 5'-CACCAGGA ACTTCTTGAATCCGG-3'). A real time thermal cycler (Rotor Gene Q, Qiagen, Germany) was used with a running profile: $37^{\circ} \mathrm{C}$ for 15 minutes, $95^{\circ} \mathrm{C}$ for 10 minutes, and a set of $95^{\circ} \mathrm{C}$ for 10 seconds, $60^{\circ} \mathrm{C}$ for 30 seconds, and $72^{\circ} \mathrm{C}$ for 30 seconds for 40 cycle repeat following by melt curve analysis from $60^{\circ} \mathrm{C}$ to $95^{\circ} \mathrm{C}$. Data were analyzed using the relative quantification method.

\subsection{Data processing and statistical analysis.}

Data obtained in all experiments were processed and statistically analyzed by a OneWay Anova approach using GraphPad Prism ${ }^{\circledR} 8$. For all statistical analyses, data were presented as mean \pm S.D and $p$ values of less than 0.05 were considered significant. 


\section{Results and Discussion}

\subsection{Expression of sodl and sod2 in response to starvation.}

Starvation is one of the approaches that can be used to increase the number of free radicals in cells $[37,38]$. The excessive free radicals can further promote the occurrence of oxidative stress, which will eventually affect the quality of life [3, 39]. To encounter such stress conditions, cells are programmed to produce endogenous antioxidants, for example, the SOD1 and SOD2 that are available from an invertebrate D. melanogaster to a more complex eukaryote such as a human.

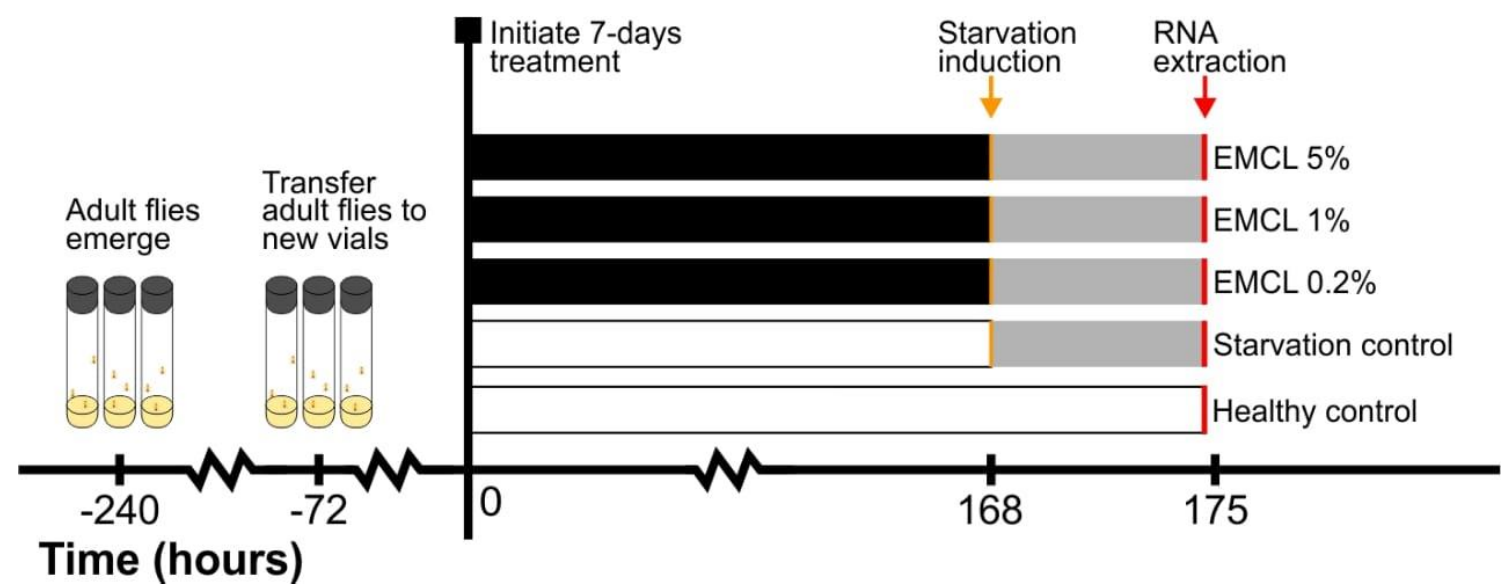

Figure 1. Timeline of the experimental design. Three groups of adult flies were subjected to treatment with food containing ethanol extract of $M$. calabura leaves (EMCL) at three different concentrations: $0.2,1$, or $5 \%$ for seven days prior to starvation for seven hours. For control groups, flies were given standard fly food in the presence (negative control) or absence (healthy control) of starvation at length, similar to treatment groups. RNA extraction was carried out at 175 hours after treatment initiation, followed by an amplification process using RT-qPCR method.

In this study, we designed an experimental approach (Fig. 1) to assess the effect of ethanol extract of M. calabura leaves (EMCL) on the expression of sod1 and sod2, two important endogenous antioxidants in Drosophila that are also available in humans.

A

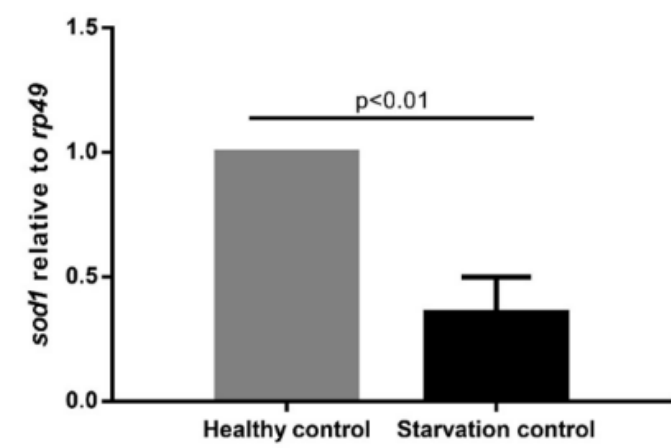

B

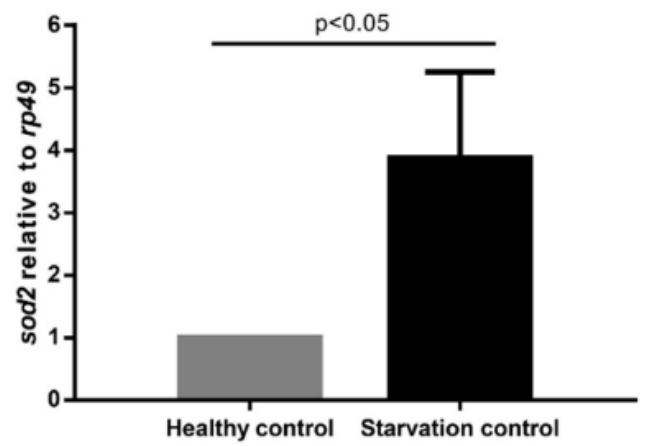

Figure 2. Levels of $\operatorname{sod} 1$ and $\operatorname{sod} 2$ gene expression in the healthy control and the starvation control groups. Adult flies were maintained and fed with standard fly food for seven days prior to starvation. After seven days, flies were transferred to either vial containing standard fly food (healthy control group) or to an empty vial (starvation control group) and incubated at $25^{\circ} \mathrm{C}$ for seven hours, followed by RNA isolation. The levels of sodl (A) and sod2 (B) were calculated compared to rp49 after amplification by RT-qPCR method.

As can be seen in Fig. 2A, it appears that the starvation control group showed reduced expression of sodl compared to the healthy control group. Surprisingly, a different result was 
obtained in the expression of sod2 (Fig. 2B). Starved Drosophila expressed a higher level of sod2 than its healthy counterpart. This might be caused by the autophagy process that can increase energy production in the mitochondria.

However, such a process also forms free radicals that can intensify sod2 production as feedback response of free radicals due to starvation condition, as has been shown previously in freshwater shrimp Neocaridina davidi [40]. Nevertheless, increased expression of sod2 gene upon starvation induction would be a beneficial response to the host because $\operatorname{sod} 2$ has been shown to be important to counteract the free radicals that first formed in the mitochondria [41].

\subsection{Effect of Muntingia calabura L. on the expression of sod1 and sod2.}

Lifespan extension is affected by several factors, including the use of endogenous antioxidants to inhibit the excessive formation of free radicals [3]. Humans and Drosophila express some endogenous antioxidants, including superoxide dismutase 1 (CuZn-SOD, SOD1) and superoxide dismutase $2(\mathrm{Mn}-S O D, S O D 2)$. Based on the results displayed in Fig. 3, it seems that the ingestion of EMCL by $D$. melanogaster before starvation-induced condition showed contrast effects on the level of expression of $\operatorname{sod} 1$ gene (Fig. 3A) and $\operatorname{sod} 2$ gene (Fig. 3B). While the expression of sodl was increased in response to EMCL treatment, the expression of $\operatorname{sod} 2$ remains unaltered.

Increased expression of sodl in response to EMCL treatment at concentrations of $1 \%$ and $5 \%$ but not at $0.2 \%$ under starvation condition may occur due to the activity of unidentified EMCL compound(s) that can activate the production of sodl in D. melanogaster in a dosedependent manner that was optimally reached at $1 \%$. Naturally, SOD1 can be found in the cytoplasm of human and D. melanogaster. This enzyme is very stable because it has noncovalent bonds formed by disulfide in each subunit [42,43]. Also, there is a possibility of this high expression related to the amount of $S O D 1$ as the dominant enzymatic antioxidant in some cells and tissues, which is an account for $70-80 \%$ of the total cellular activity of SODs, as has been shown in mice and human cells [44-46].

Surprisingly, while the induction of sod2 expression was observed in response to starvation (Fig. 2B), EMCL treatment demonstrated no stimulatory effect on the expression level of sod2 in starved D. melanogaster (Fig. 3B).

A

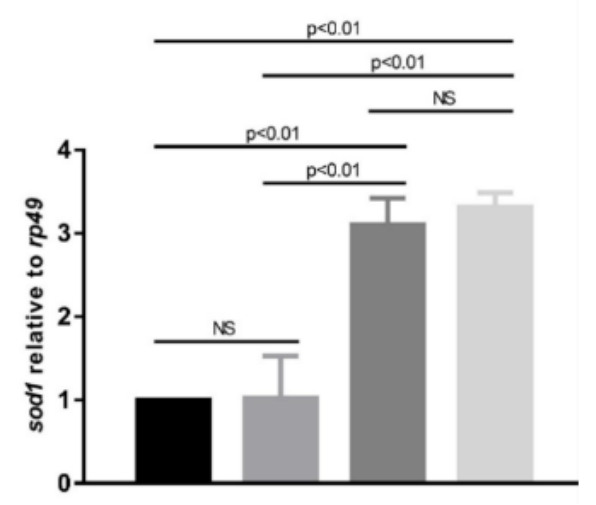

B

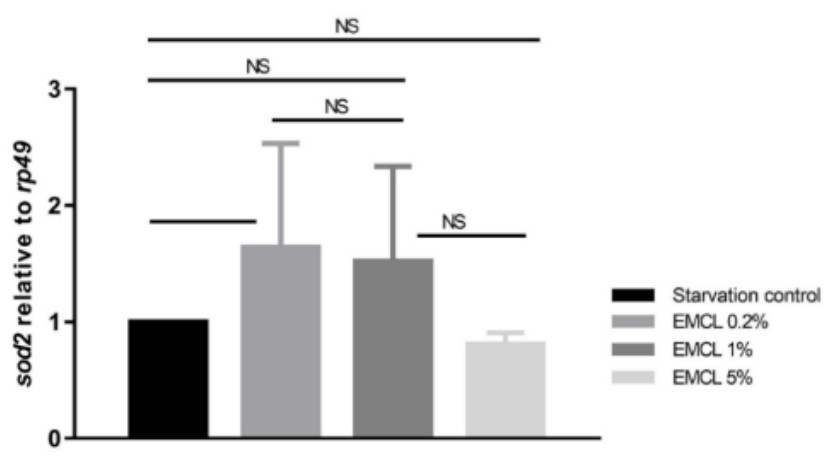

Figure 3. Levels of sodl and sod2 gene expression in the starvation control and ethanol extract of Muntingia calabura (EMCL)-treated groups. Adult flies were maintained and fed with standard fly food for seven days before starvation. After seven days, flies were transferred to empty vials and incubated at $25^{\circ} \mathrm{C}$ for seven hours, followed by RNA isolation. The levels of $\operatorname{sod} 1$ (A) and $\operatorname{sod} 2$ (B) were calculated compared to rp49 after amplification by RT-qPCR method. 
The reason(s) why these unexpected results have occurred remains unknown. Nevertheless, taken together, our results implied that starvation could induce the expression of sod 2 but not sod1, and this expression profile was reversed under EMCL treatment at certain concentrations (1\% and 5\%).

In addition to the sod genes, a thorough investigation on the effect of EMCL on the expression of some genes known to express endogenous antioxidants (for example, cat gene that expresses catalase) will provide additional information on the prospective use of EMCL in the modulation of endogenous antioxidants. In the long run, follow-up research is urgently required to elucidate the responsible compound(s) in the modulation of sod1 and sod2 expression and also to unveil the detailed mechanisms on how such compound(s) can yield the demonstrated effects.

\section{Conclusions}

In the current study, we provided initial evidence that the expression of endogenous antioxidants sod1 and sod2 in D. melanogaster was modulated by starvation. The administration of ethanol extract of Muntingia calabura L. leaves (EMCL) was able to induce the expression of sod 1 but not sod 2 in starved D. melanogaster. Here, we reported the potential in vivo anti-aging effect of EMCL in a Drosophila platform system that shall warrant future research in higher model animals or even human subjects.

\section{Funding}

This research received no external funding.

\section{Acknowledgments}

We want to offer our appreciation to Prof. Yoshinobu Nakanishi (Kanazawa University, Japan) for his kind support in providing the Drosophila line used in this study and Prof. Elly Wahyudin (Hasanuddin University, Indonesia) for her generous support in the use of research facilities at Biofarmaka Laboratory.

\section{Conflicts of Interest}

The authors declare no conflict of interest.

\section{References}

1. Alkadi, H. A Review on Free Radicals and Antioxidants. Infect Disord Drug Targets 2020, 20, 16-26, https://doi.org/10.2174/1871526518666180628124323.

2. Di Meo, S.; Venditti, P. Evolution of the Knowledge of Free Radicals and Other Oxidants. Oxid Med Cell Longev 2020, 2020, https://doi.org/10.1155/2020/9829176.

3. Liguori, I.; Russo, G.; Curcio, F.; Bulli, G.; Aran, L.; Della-Morte, D.; Gargiulo, G.; Testa, G.; Cacciatore, F.; Bonaduce, D.; Abete, P. Oxidative stress, aging, and diseases. Clin Interv Aging 2018, 13, 757-772, https://doi.org/10.2147/CIA.S158513.

4. Singh, A.; Kukreti, R.; Saso, L.; Kukreti, S. Oxidative Stress: A Key Modulator in Neurodegenerative Diseases. Molecules 2019, 24, https://doi.org/10.3390/molecules24081583.

5. Zarkovic, N. Roles and Functions of ROS and RNS in Cellular Physiology and Pathology. Cells 2020, 9 , https://doi.org/10.3390/cells9030767.

6. Kannan, K.; Jain, S.K. Oxidative stress and apoptosis. Pathophysiology 2000, 7, 153-163, https://doi.org/10.1016/s0928-4680(00)00053-5. 
7. Nainu, F.; Shiratsuchi, A.; Nakanishi, Y. Induction of apoptosis and subsequent phagocytosis of virusinfected cells as an antiviral mechanism. Front Immunol 2017, 8, 1220-1220, https://doi.org/10.3389/fimmu.2017.01220.

8. MatÉs, J.M.; Pérez-Gómez, C.; De Castro, I.N. Antioxidant enzymes and human diseases. Clinical Biochemistry 1999, 32, 595-603, https://doi.org/10.1016/S0009-9120(99)00075-2.

9. Elmore, S. Apoptosis: a review of programmed cell death. Toxicol Pathol 2007, 35, 495-516, https://doi.org/10.1080/01926230701320337.

10. Nikoletopoulou, V.; Markaki, M.; Palikaras, K.; Tavernarakis, N. Crosstalk between apoptosis, necrosis and autophagy. Biochimica et Biophysica Acta (BBA) - Molecular Cell Research 2013, 1833, 3448-3459, https://doi.org/10.1016/j.bbamcr.2013.06.001.

11. Suzuki, S. W.; Onodera, J.; Ohsumi, Y. Starvation Induced Cell Death in Autophagy-Defective Yeast Mutants Is Caused by Mitochondria Dysfunction. PLOS ONE 2011, 6, https://doi.org/10.1371/journal.pone.0017412.

12. Liang, Y.; Liu, C.; Lu, M.; Dong, Q.; Wang, Z.; Wang, Z.; Xiong, W.; Zhang, N.; Zhou, J.; Liu, Q.; Wang, $\mathrm{X}$.; Wang, Z. Calorie restriction is the most reasonable anti-ageing intervention: a meta-analysis of survival curves. Scientific Reports 2018, 8, https://doi.org/10.1038/s41598-018-24146-Z.

13. Flurkey, K.; Astle, C.M.; Harrison, D.E. Life extension by diet restriction and N-acetyl-L-cysteine in genetically heterogeneous mice. J Gerontol A Biol Sci Med Sci 2010, 65, 1275-1284, https://doi.org/10.1093/gerona/glq155.

14. Le Bourg, É. Life Extension: Lessons from Drosophila. ed. Vaiserman, A.M. (Cham: Springer International Publishing), 2015; pp 301-320.

15. Rahmatika, D.; Kuroda, N.; Min, Z.; Nainu, F.; Nagaosa, K.; Nakanishi, Y. Inhibitory effects of viral infection on cancer development. Virology 2019, 528, 48-53, https://doi.org/10.1016/j.virol.2018.12.008.

16. Hay, B.A.; Guo, M. Caspase-dependent cell death in Drosophila. Annu Rev Cell Dev Biol 2006, 22, 623650, https://doi.org/10.1146/annurev.cellbio.21.012804.093845.

17. Asri, R.M.; Salim, E.; Nainu, F.; Hori, A.; Kuraishi, T. Sterile induction of innate immunity in Drosophila melanogaster. Frontiers in Bioscience (Landmark Edition) 2019, 24, 1390-1400, http://dx.doi.org/10.2741/4786.

18. Buchon, N.; Silverman, N.; Cherry, S. Immunity in Drosophila melanogaster--from microbial recognition to whole-organism physiology. Nat Rev Immunol 2014, 14, 796-810, https://doi.org/10.1038/nri3763.

19. Nainu, F.; Tanaka, Y.; Shiratsuchi, A.; Nakanishi, Y. Protection of insects against viral infection by apoptosis-dependent phagocytosis. Journal of Immunology 2015, 195, 5696-5706, https://doi.org/10.4049/jimmunol.1500613.

20. Swevers, L.; Liu, J.; Smagghe, G. Defense mechanisms against viral infection in Drosophila: RNAi and non-RNAi. Viruses 2018, 10, https://doi.org/10.3390/v10050230.

21. Panayidou, S.; Ioannidou, E.; Apidianakis, Y. Human pathogenic bacteria, fungi, and viruses in Drosophila: disease modeling, lessons, and shortcomings. Virulence 2014, 5, 253-269, https://doi.org/10.4161/viru.27524.

22. Nainu, F.; Asri, R.M.; Arsyad, A.; Manggau, M.A.; Amir, M.N. In vivo antibacterial activity of green algae Ulva reticulata against Staphylococcus aureus in Drosophila model of infection. Pharmacognosy Journal 2018, 10, 993-997, https://doi.org/10.5530/pj.2018.5.169.

23. Nainu, F.; Asri, R.M.; Djide, M.N.; Ahsan, M.; Arfiansyah, R.; Sartini, S.; Alam, G. Protective effect of green algae Ulva reticulata against Pseudomonas aeruginosa in Drosophila infection model. HAYATI Journal of Biosciences 2019, 26, 163-171.

24. Nainu, F.; Djide, M.N.; Subehan, S.; Sartini, S.; Roska, T.P.; Salim, E.; Kuraishi, T. Protective Signatures of Roselle (Hibiscus sabdariffa L.) Calyx Fractions against Staphylococcus aureus in Drosophila Infection Model. HAYATI Journal of Biosciences 2020, 27, 306-313.

25. Ahsan, M.; Gonsales, A. V.; Sartini, S.; Wahyudin, E.; Nainu, F. In vivo anti-staphylococcal activity of roselle (Hibiscus sabdariffa L.) calyx extract in Drosophila model of infection. Journal of Herbmed Pharmacology 2019, 8, 41-46, https://doi.org/10.15171/jhp.2019.07.

26. Ekowati, H.; Arai, J.; Putri, A.S.D.; Nainu, F.; Shiratsuchi, A.; Nakanishi, Y. Protective effects of Phaseolus vulgaris lectin against viral infection in Drosophila. Drug Discoveries and Therapeutics 2017, 11, 329-335, https://doi.org/10.5582/ddt.2017.01071.

27. Fernández-Hernández, I.; Scheenaard, E.; Pollarolo, G.; Gonzalez, C. The translational relevance of Drosophila in drug discovery. EMBO Rep 2016, 17, 471-472, https://doi.org/10.15252/embr.201642080.

28. Nainu, F.; Rahmatika, D.; Emran, T.B.; Harapan, H. Potential Application of Drosophila melanogaster as a Model Organism in COVID-19-Related Research. Frontiers in Pharmacology 2020, 11, https://doi.org/10.3389/fphar.2020.588561.

29. Zelko, I.N.; Mariani, T.J.; Folz, R.J. Superoxide dismutase multigene family: a comparison of the CuZnSOD (SOD1), Mn-SOD (SOD2), and EC-SOD (SOD3) gene structures, evolution, and expression. Free Radic Biol Med 2002, 33, 337-349, https://doi.org/10.1016/s0891-5849(02)00905-x. 
30. Ighodaro, O.M.; Akinloye, O.A. First line defence antioxidants-superoxide dismutase (SOD), catalase (CAT) and glutathione peroxidase (GPX): Their fundamental role in the entire antioxidant defence grid. Alexandria Journal of Medicine 2018, 54, 287-293, https://doi.org/10.1016/j.ajme.2017.09.001.

31. Tower, J. Life Extension: Lessons from Drosophila. ed Vaiserman, A.M. (Cham: Springer International Publishing) 2015; pp. 67-81

32. Sun, J.; Tower, J. FLP recombinase-mediated induction of $\mathrm{Cu} / \mathrm{Zn}$-superoxide dismutase transgene expression can extend the life span of adult Drosophila melanogaster flies. Mol Cell Biol 1999, 19, 216-228, https://doi.org/10.1128/mcb.19.1.216.

33. Shin-Hae, L.; Kyung-Jin, M. Life Extension: Lessons from Drosophila. Ed Vaiserman, A.M. (Cham: Springer International Publishing), 2015; pp. 229-244

34. Kang, H.-L.; Benzer, S.; Min, K.-T. Life extension in Drosophila by feeding a drug. Proceedings of the National Academy of Sciences 2002, 99, 838-843, https://doi.org/10.1073/pnas.022631999.

35. Sulistyoningrum, E.; Rosmelia, R.; Hamid, M.K.; Nuraini, W.S.T. Anti-aging effects of Muntingia calabura leaves extract in D-galactose-induced skin aging mouse model. Journal of Applied Pharmaceutical Science 2019, 9, 23-29, https://doi.org/10.7324/JAPS.2019.90904.

36. Mahmood, N.D.; Nasir, N.L.M.; Rofiee, M.S.; Tohid, S.F.M.; Ching, S.M.; Teh, L.K.; Salleh, M.Z.; Zakaria, Z.A. Muntingia calabura: A review of its traditional uses, chemical properties, and pharmacological $\begin{array}{lllll}\text { observations. } & \text { Pharmaceutical } & \text { Biology } & \text { 2014, } & \text { 52, }\end{array}$ https://doi.org/10.3109/13880209.2014.908397.

37. Robinson, M.K.; Rustum, R.R.; Chambers, E.A.; Rounds, J.D.; Wilmore, D.W.; Jacobs, D.O. Starvation enhances hepatic free radical release following endotoxemia. The Journal of Surgical Research 1997, 69, 325-330, https://doi.org/10.1006/jsre.1997.5062.

38. Li, L.; Chen, Y.; Gibson, S.B. Starvation-induced autophagy is regulated by mitochondrial reactive oxygen species leading to AMPK activation. Cellular Signalling 2013, 25, 50-65, https://doi.org/10.1016/j.cellsig.2012.09.020.

39. Le Bourg, É. Oxidative stress, aging and longevity in Drosophila melanogaster. FEBS Letters 2001, 498, 183-186, https://doi.org/10.1016/S0014-5793(01)02457-7.

40. Włodarczyk, A.; Wilczek, G.; Wilczek, P.; Student, S.; Ostróżka, A.; Tarnawska, M.; Rost-Roszkowska, M. Relationship between ROS production, MnSOD activation and periods of fasting and re-feeding in freshwater shrimp Neocaridina davidi (Crustacea, Malacostraca). PeerJ 2019, 7, e7399-e7399, https://doi.org/10.7717/peerj.7399.

41. Sena, L.A.; Chandel, N.S. Physiological roles of mitochondrial reactive oxygen species. Molecular Cell 2012, 48, 158-167, https://doi.org/10.1016/j.molcel.2012.09.025.

42. Field, L.S.; Furukawa, Y.; O'Halloran, T.V.; Culotta, V.C. Factors controlling the uptake of yeast copper/zinc superoxide dismutase into mitochondria. The Journal of Biological Chemistry 2003, 278, 28052-28059, https://doi.org/10.1074/jbc.M304296200.

43. Furukawa, Y.; O'Halloran, T.V. Posttranslational modifications in Cu,Zn-superoxide dismutase and mutations associated with amyotrophic lateral sclerosis. Antioxidants \& Redox Signaling 2006, 8, 847-867, https://doi.org/10.1089/ars.2006.8.847.

44. Liu, Y.; Zha, L.; Li, B.; Zhang, L.; Yu, T.; Li, L. Correlation between superoxide dismutase 1 and 2 polymorphisms and susceptibility to oral squamous cell carcinoma. Exp Ther Med 2014, 7, 171-178, https://doi.org/10.3892/etm.2013.1375.

45. Weydert, C.J.; Cullen, J.J. Measurement of superoxide dismutase, catalase and glutathione peroxidase in cultured cells and tissue. Nature Protocols 2010, 5, 51-66, https://doi.org/10.1038/nprot.2009.197.

46. Remmen, H.V.; Williams, M.D.; Guo, Z.; Estlack, L.; Yang, H.; Carlson, E.J.; Epstein, C.J.; Huang, T. T.; Richardson, A. Knockout mice heterozygous for Sod2 show alterations in cardiac mitochondrial function and apoptosis. American Journal of Physiology-Heart and Circulatory Physiology 2001, 281, H1422H1432, https://doi.org/10.1152/ajpheart.2001.281.3.H1422. 